\title{
HoLe MaKing IN GAMMa TiAL
}

\author{
BeranoAgirre, A.; OlverA, D.; UrbiCAIN, G.; LOPEZ DE \\ LACALLE, L.N. \& LAMIKIZ, A.
}

Abstract: Due to their high strength/weight ratio and resistance to corrosion and wear, super alloys such as gamma TiAl or Inconel 718 appear as the best choice at the sight of the demands in the vicinity of the combustion chamber for aeronautical engines. Such kind of parts experience one last drilling operation at the end of the manufacturing process what could jeopardize the work integrity adding new costs. Within this context, the paper presents the results obtained from several tests in gamma TiAl alloys using two different strategies: traditional drilling and ball helical milling. At first instance, tool life tests were performed on three types of $\gamma$-TiAl alloys (extruded MoCuSi, ingot MoCuSi and TNB) to define an optimal set of cutting parameters. Then, a new technique, ball helical milling, was studied as an alternative to traditional drilling when dealing with $\gamma$-TiAl. This technique has shown special promising results in such kind of materials.

Key words: Gamma TiAl, Ti-6Al-4V, drilling, helical milling
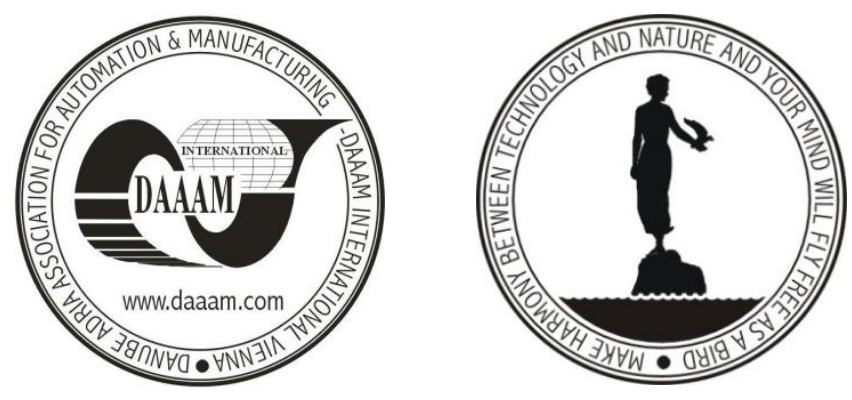

Authors' data: Eng. Beranoagirre, A[itor $]^{*}$; Eng. Olvera, D[avid]**; Eng. Urbicain, G[orka]**; Univ.Prof. Dr. Eng. Lopez de Lacalle, L[uis] N[orberto]**; Dr. Eng. Lamikiz, A[itzol] **, *University of the Basque Country Avda. Tolosa,20018, San Sebastián, Spain, ** University of the Basque Country, UPVETSI, Alameda Urquijo s/n, 48013, Bilbao, Spain, aitor.beranoagirre@ehu.es, david_olvera@ehu.es, bckurpeg@ehu.es, norberto.lzlacalle@ehu.es, aitzol.lamikiz@ehu.es

This Publication has to be referred as: Beranoagirre, A[itor]; Olvera, D[avid]; Urbicain, G[orka]; Lopez de Lacalle, L[uis] N[orberto] \& Lamikiz, A[itzol] (2010). Hole Making in Gamma Tial, Chapter 32 in DAAAM International Scientific Book 2010, pp. 337-346, B. Katalinic (Ed.), Published by DAAAM International, ISBN 978-3-901509-74-2, ISSN 1726-9687, Wien, Austria

DOI: $10.2507 /$ daaam.scibook.2010.32 


\section{Introduction}

One of the challenges of civil aviation in future years is based on reducing specific fuel consumption per passenger. Hence, the interest of the air transport industry focused on the research of new materials that would open the way to support more demanding service conditions with the restriction of a lighter aircraft. Any improvement in one or more of the above conditions is a guarantee of competitiveness in a future where estimations on passengers and cargo are expected to rise.

Regarding to the aircraft engine, $\gamma$-TiAl inter metallic super alloys appear as a valid alternative in direct competition with nickel-based super alloys (Inconel, Wasp alloy) where service temperatures exceed $800^{\circ} \mathrm{C}$. These alloys find theirmarket in the high pressure area (compressor blades and stator) as well as in the low pressure zones (blades). The binomial TiAl provides a low density as well as high mechanical strength under high temperatures and corrosive environments (Loria, 2001). While their chances look promising, the leap from research and production of such type of advanced materials to their incorporation into an aircraft engine has been rather problematic due to the high tolerances imposed by the aero space sector where the requirements of reliability against fatigue and creep failure do not allow their inclusion in the current state of knowledge. These are complex alloys with high sensitivity to non-metallic impurities such as oxygen which need to be studied further.

The main difference between $\gamma$-TiAl alloy and other alloys such as Ti-6Al-4V lies on the aluminum levels (43-48\% in $\gamma$-TiAl and 6\% in Ti-6Al-4V) which improves thermal conductivity in $\gamma$-TiAl but worsening the ductile transition temperature which occurs between $600-800^{\circ} \mathrm{C}$, depending on the microstructure and grain size.

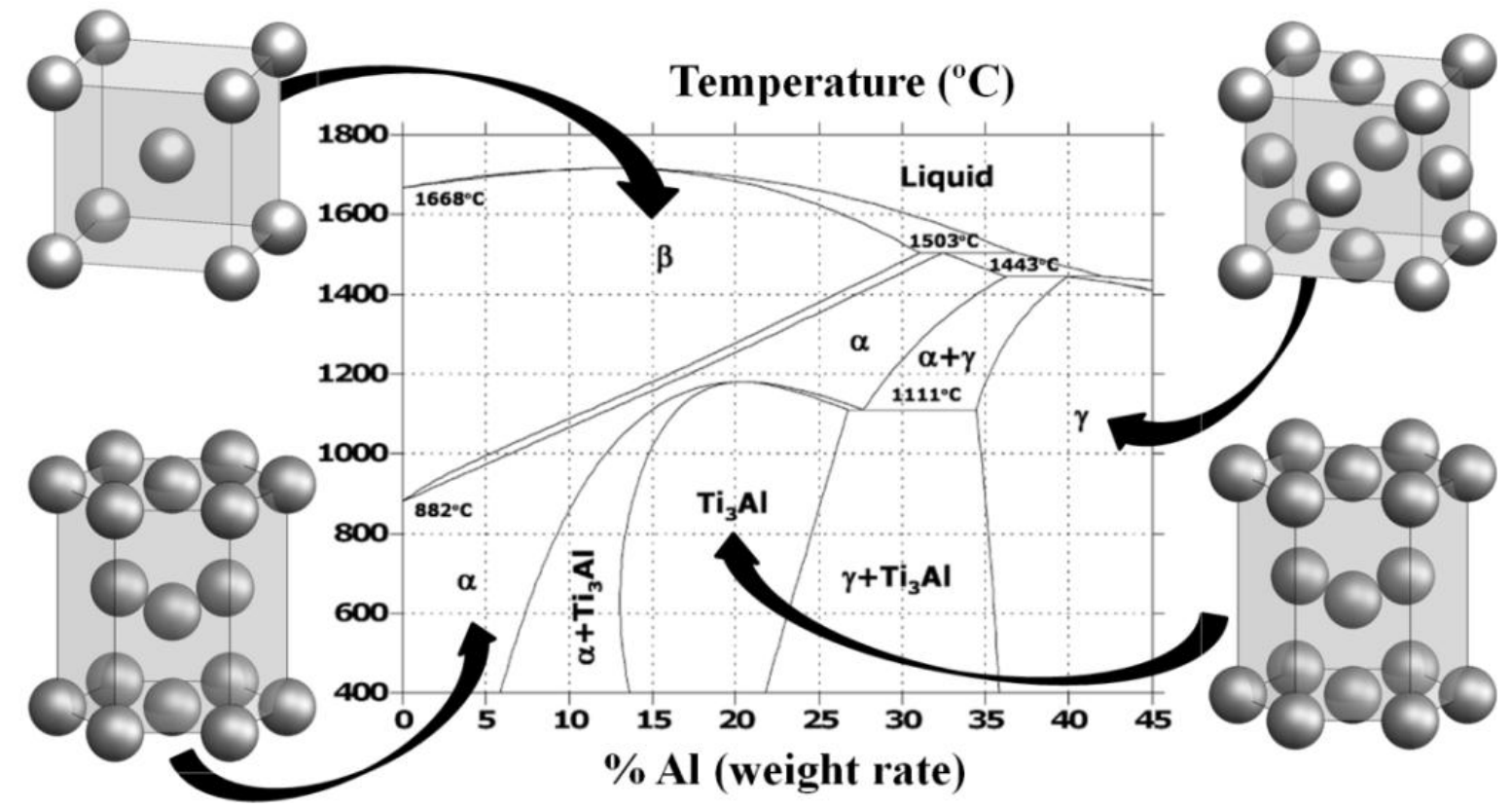

Fig. 1. TiAl phases diagram and crystal structure of alpha (HCP), beta (BCC), alpha2 or $\mathrm{Ti}_{3} \mathrm{Al}(\mathrm{HCP})$ and gamma (FCC) phases 
In solid state, titanium alloys are found as alpha HCP (hexagonal close-packed structure)or beta BCC (body-centered cubic structure) phase. In pure state, the transition temperature between two phases is found at $882^{\circ} \mathrm{C}$, TiAl couple enabling solid solution hardening. Aluminum is the most common alloying element because of its ability to raise the beta transition temperature and its high solubility in both phases. Besides the alpha and beta phases, alpha 2 or $\mathrm{Ti}_{3} \mathrm{Al}$ and inter metallic gamma phase appear, both of capital significance in high temperature aerospace applications. The latter one is a face-centered cubic (FCC) $\mathrm{L}_{0}$ phase whose homogeneity ranges between 34 to55\% ( $\%$ in weight). Fig. 1 shows the relationship between microstructure and phase. The aluminum, oxygen, hydrogen and other alpha stabilizers increase the transition temperature between alpha/beta phases. On the other hand, beta-stabilizers (beta-eutectoid and beta-isomorphic) reduce the transformation temperature, causing a stable beta phase at room temperature.

The following paper deals with the study of the behaviour of complex difficult-to-cut super alloys such as $\gamma$-TiAl (Sharman et al., 2001). Tool life tests have helped in defining a suitable set of parameters in drilling of three different types of $\gamma$-TiAl (extruded $\mathrm{MoCuSi}$, ingot $\mathrm{MoCuSi}$ and $\mathrm{TNB}$ ). Next to it, an alternative technique based on ball helical milling is introduced for the hole making process. This operation based on a ball mill describing a helical path has proved to be more efficient than conventional drilling.

\section{Drilling of $\gamma$-TiAl super alloy}

The inter metallic gamma TiAl super alloys offer excellent mechanical properties (Loria, 2001), with low $4 \mathrm{gr} / \mathrm{cm}^{3}$ density, high resistance at high temperatures, low electrical and thermal conductivity, oxidation resistance, ultimate strength of 1000Mpa and Young's modulus of $160 \mathrm{Gpa}$ (Aspinwal et al., 2007). There are three basic types of $\gamma$-TiAl super alloys: TNB [(44-45)Al-(5-10)Nb-(0.2-0.4)C], sustaining high levels of mechanical and oxidation resistance and used in aircraft applications at high temperatures(Noda, 1999; Smit et al., 1999); MoCuSi type [(43-46)Al-(1-2)Mo(0.2) $\mathrm{Si}-\mathrm{Cu}$ ], for low temperatures applications and with high resistance below $650^{\circ}$ $\mathrm{C}$; finally, TNM [(43-45)Al-(5-8) Nb-Mo- $(0-0,4) \mathrm{BC}]$ for high temperature applications. There are two ways to manufacture these materials: solidified ingot or extruded alloy. In the first case, the alloy has the microstructure oriented in the direction of extrusion whereas in the case of melted and solidified alloys in the mould, the microstructure has no preferred orientation.

Those kinds of materials are known by their low mach inability and a study of the optimal cutting conditions seems necessary. Table 1 shows the basic cutting data investigated during the experimental drilling trials. A set of optimal cutting parameters for a reasonable tool life were obtained in extruded $\mathrm{MoCuSi}$, ingot $\mathrm{MoCuSi}$ and TNB. 


\begin{tabular}{|c|c|c|c|c|c|}
\hline \multirow{2}{*}{$\mathbf{v}_{\mathbf{c}}[\mathbf{m} / \mathbf{m i n}]$} & \multicolumn{5}{|c|}{$\mathbf{f}_{\mathbf{n}}[\mathbf{m m} / \mathbf{m i n}]$} \\
\cline { 2 - 6 } & $\mathbf{0 . 0 2 5}$ & $\mathbf{0 . 0 3 8}$ & $\mathbf{0 . 0 5 0}$ & $\mathbf{0 . 1 0 0}$ & $\mathbf{0 . 1 5 0}$ \\
\hline $\mathbf{1 0}$ & $\mathrm{M}_{1}, \mathrm{M}_{3}$ & $\mathrm{M}_{1}, \mathrm{M}_{3}$ & $\mathrm{M}_{1}, \mathrm{M}_{2}, \mathrm{M}_{3}$ & $\mathrm{M}_{1}, \mathrm{M}_{2}, \mathrm{M}_{3}$ & $\mathrm{M}_{2}, \mathrm{M}_{3}$ \\
\hline $\mathbf{1 5}$ & $\mathrm{M}_{1}$ & $\mathrm{M}_{1}$ & $\mathrm{M}_{1}, \mathrm{M}_{2}, \mathrm{M}_{3}$ & $\mathrm{M}_{1}, \mathrm{M}_{2}, \mathrm{M}_{3}$ & \\
\hline $\mathbf{2 0}$ & $\mathrm{M}_{1}$ & $\mathrm{M}_{1}$ & $\mathrm{M}_{1}, \mathrm{M}_{2}, \mathrm{M}_{3}$ & & \\
\hline $\mathbf{2 5}$ & $\mathrm{M}_{1}$ & & & & \\
\hline
\end{tabular}

Tab. 1. Tests procedure: $\mathrm{M}_{1}=$ extruded $\mathrm{MoCuSi}, \mathrm{M}_{2}=$ ingot $\mathrm{MoCuSi}, \mathrm{M}_{3}=\mathrm{TNB}$

Tests were carried out using carbide tools whose main geometrical characteristics are shown in Fig.2. One of the critical aspects when drilling $\gamma$-TiAl is heat dissipation and chip evacuation due to the poor thermal conductivity. Regarding to this, cutting tools are endowed with internal lubrication directly applied on the cutting edge, favouring chip evacuation. The cutting tools used were drills of $\varnothing 4$ and TF15 quality with Young's modulus of $580 \mathrm{GPa}$ and MIRACLE (Al,Ti)N coating type. The operations were performed for a depth of $20 \mathrm{~mm}(\mathrm{D} / \mathrm{L}=5)$ under a pressure of 8.5 bar for the coolant.

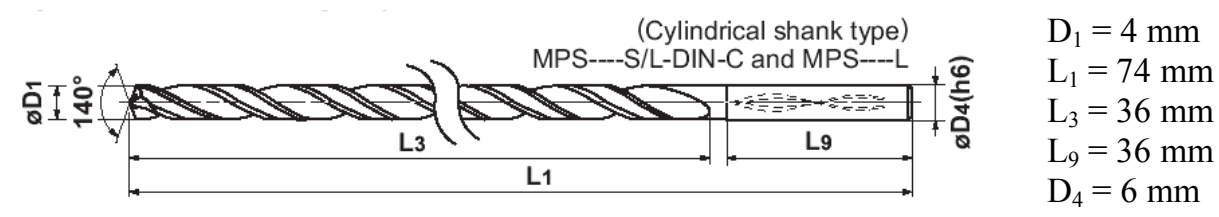

Fig. 2. Cutting tool geometry.

The wear on the cutting edges of the tool was observed with a Motic SMZ microscope and the measurements were made on the digitized image of the tool. The well-known criterion $\mathrm{Vb}=0.3$ of flank wear width, typical for turning operations, was employed: values above $0.3 \mathrm{~mm}$ were considered unacceptable. Fig. 3, 4 and 5 show the wear curves under different cutting speeds for the three types of $\gamma$-TiAl alloys.

Extruded MoCuSi:

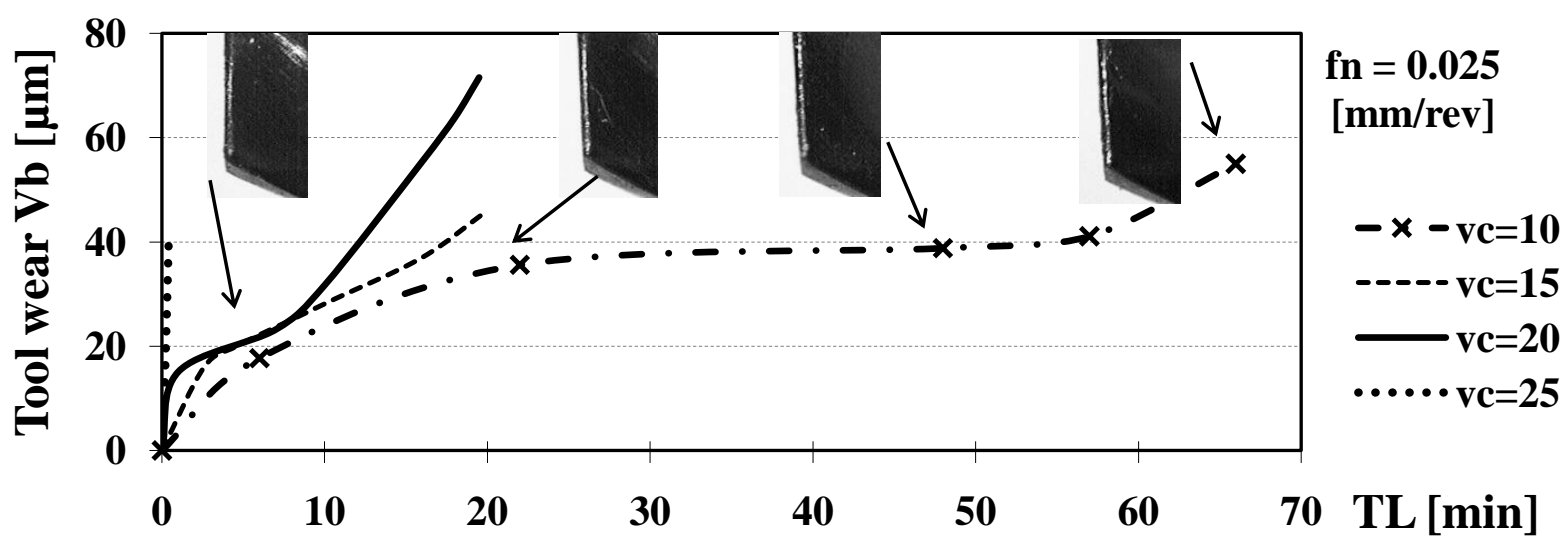

Fig. 3. Tool life in extruded MoCuSi (TL=Tool Life) 


\section{Ingot MoCuSi:}

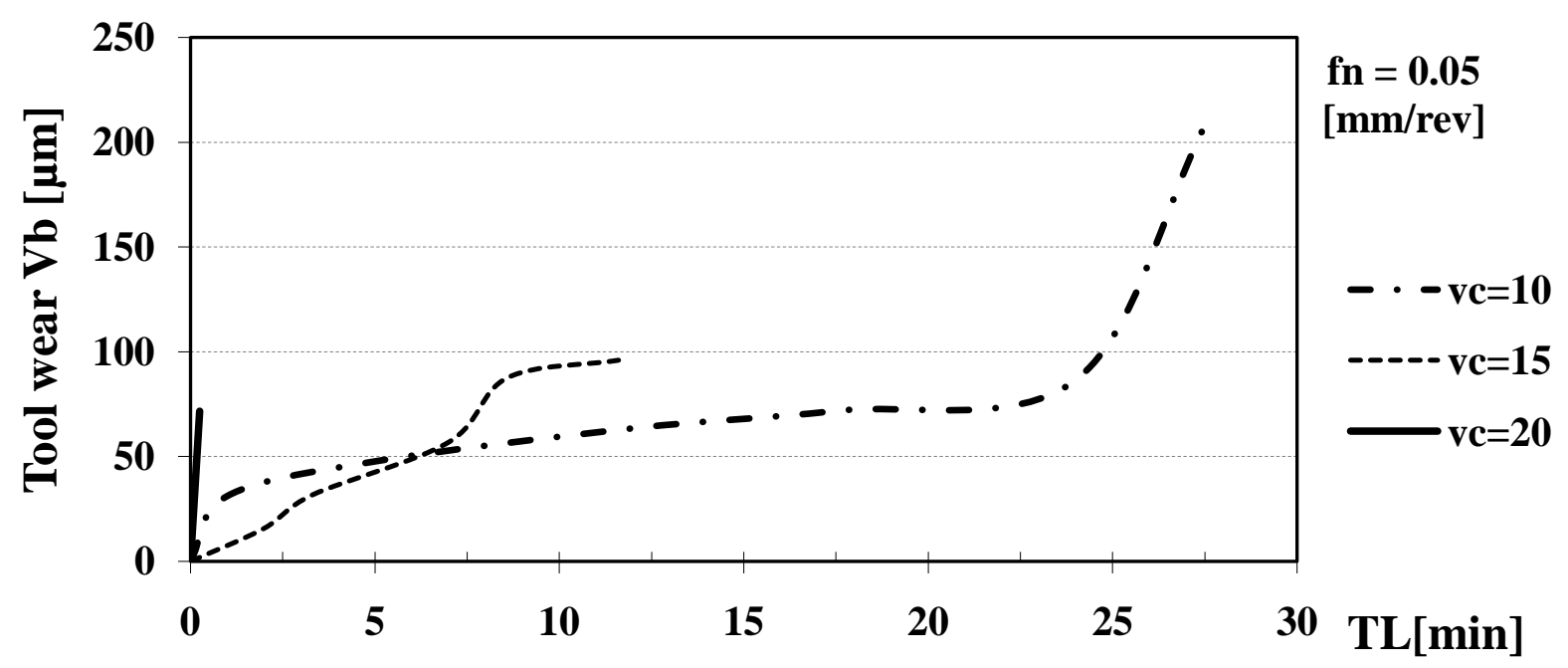

Fig. 4. Tool life in ingot MoCuSi (TL=Tool Life)

TNB:

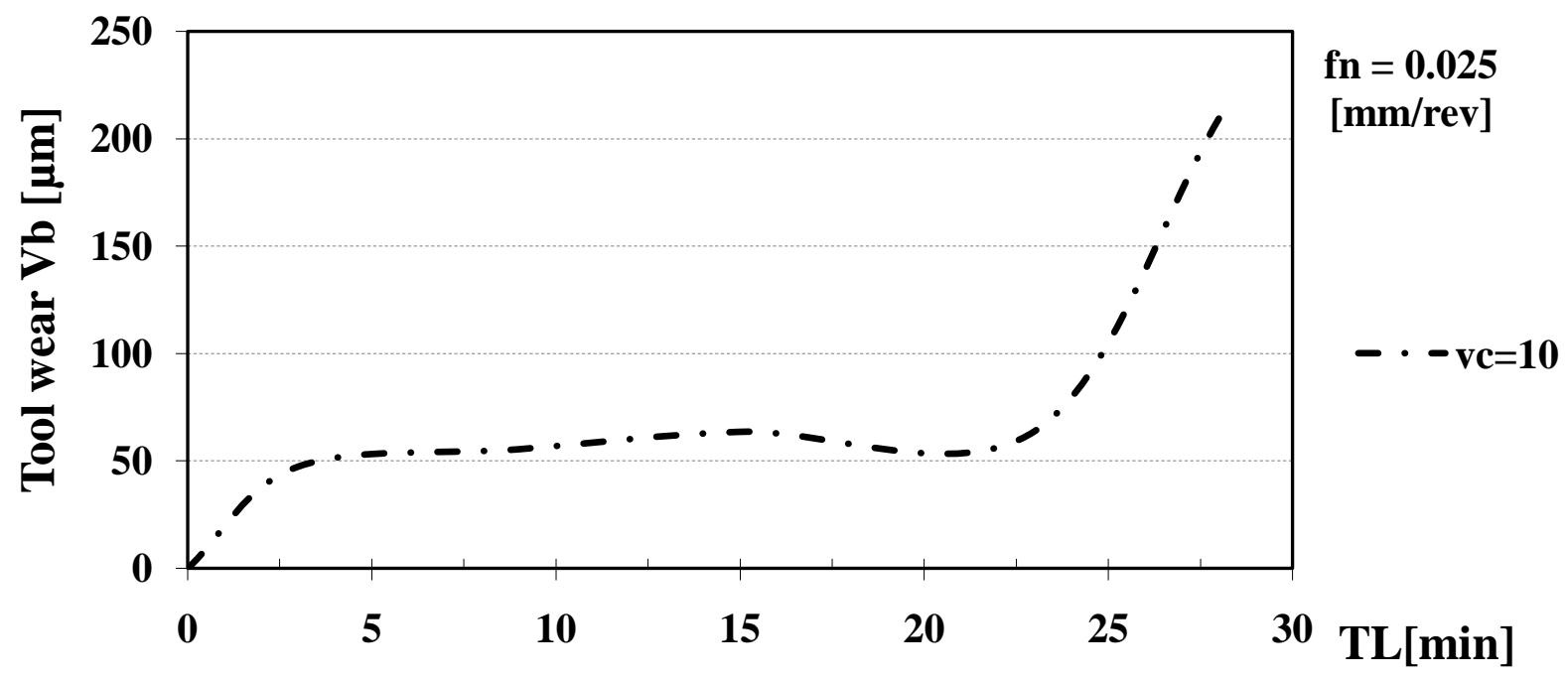

Fig. 5.Tool life in TNB (TL=Tool Life)

Table 2 shows that, for the same cutting conditions, the tool has a longer life, 3 times higher when machining MoCuSi ingot than in TNB. In general, for the three materials it can be stated that the optimal speed range is between $10-15 \mathrm{~m} / \mathrm{min}$. Higher speeds lead to accelerated wear of the tool, except in the case of extruded MoCuSi where machining times are about $20 \mathrm{~min}$ when $\mathrm{f}_{\mathrm{n}}=0.025 \mathrm{~mm} / \mathrm{rev}$.

Another aspect is the strong tendency of the drill to torsion failure which is very sensitive to an increase in cutting speed. This failure occurs catastrophically at approximately $45^{\circ}$ of the profile of the drill. 
Beranoagirre, A.; Olvera, D.; Urbicain, G.; Lopez de Lacalle, L. N. \& Lamikiz, A.: Hole...

\begin{tabular}{|c|c|c|c|c|c|c|c|}
\hline \multirow{2}{*}{$\begin{array}{c}\mathrm{V}_{\mathrm{c}} \\
{[\mathrm{m} / \mathrm{min}]}\end{array}$} & \multirow[b]{2}{*}{$\begin{array}{c}\mathrm{f}_{\mathrm{n}} \\
{[\mathrm{mm} / \mathrm{rev}]}\end{array}$} & \multicolumn{2}{|c|}{ Extruded MoCuSi } & \multicolumn{2}{|c|}{ Ingot MoCuSi } & \multicolumn{2}{|c|}{ TNB } \\
\hline & & Time[min] & $\begin{array}{l}\text { Wear } \\
{[\mu \mathrm{m}]}\end{array}$ & $\begin{array}{l}\text { Time } \\
\text { [min] }\end{array}$ & $\begin{array}{l}\text { Wear } \\
{[\mu \mathrm{m}]}\end{array}$ & $\begin{array}{l}\text { Time } \\
{[\mathrm{min}]}\end{array}$ & $\begin{array}{l}\text { Wear } \\
{[\mu \mathrm{m}]}\end{array}$ \\
\hline \multirow{4}{*}{10} & 0.025 & 66 & 55 & - & - & 28 & 209.2 \\
\hline & 0.038 & 13.3 & 52.4 & - & - & 17.8 & 95.7 \\
\hline & 0.05 & 5.5 & 58.6 & 27.5 & 208 & 9.5 & 85 \\
\hline & 0.1 & 3 & 60 & 5 & 168.5 & 4.5 & 83.7 \\
\hline \multirow{4}{*}{15} & 0.025 & 20 & 46 & - & - & - & - \\
\hline & 0.038 & 8.3 & 31.2 & - & - & - & - \\
\hline & 0.05 & 2.4 & 30 & 11.6 & 96 & 8 & 79.9 \\
\hline & 0.1 & & - & 2 & 93 & 0.5 & 55.4 \\
\hline \multirow{4}{*}{20} & 0.025 & 19.5 & 71.5 & - & - & - & - \\
\hline & 0.038 & - & - & - & - & - & - \\
\hline & 0.05 & - & - & 0.25 & 71.5 & 2 & 63.5 \\
\hline & 0.1 & - & - & - & - & - & - \\
\hline \multirow{4}{*}{25} & 0.025 & 0.4 & 39.3 & - & - & - & - \\
\hline & 0.038 & - & - & - & - & - & - \\
\hline & 0.05 & - & - & - & - & - & - \\
\hline & 0.1 & - & - & - & - & - & - \\
\hline
\end{tabular}

Tab. 2. Tool life and wear vs materials/cutting conditions

Based on the results shown in the table, the following conditions are recommended for each one of the mentioned materials:

- extruded MoCuSi: $\mathrm{v}_{\mathrm{c}}=10-15 \mathrm{~m} / \mathrm{min}, \mathrm{f}_{\mathrm{n}}=0.025 \mathrm{~mm} / \mathrm{rev}$

- MoCuSi ingot: $\mathrm{v}_{\mathrm{c}}=10-15 \mathrm{~m} / \mathrm{min}, \mathrm{f}_{\mathrm{n}}=0.050 \mathrm{~mm} / \mathrm{rev}$

- TNB: $\mathrm{v}_{\mathrm{c}}=10-15 \mathrm{~m} / \mathrm{min}, \mathrm{f}_{\mathrm{n}}=0.025 \mathrm{~mm} / \mathrm{rev}$

\section{Ball helical milling of $\gamma$-TiAl super alloy}

Drilling operation offers a good compromise between surface quality, tool life and speed operation being the adopted solution in most of the cases.However, when the tolerances imposed over the part force new operations (re-drilling, reaming), the time (costs) of manufacture is increased. In these cases, tool change and new processes added to the work piece should be avoided and minimized and the helical milling using an end ball mill appears as a feasible alternative as shown by Iyer et al. (Iyer et al., 2006). This process is basically defined as a superposition of two motions: a rotation of the tool on its own axis and a helical translation where the feed rate is defined with the translation speed over the helical path. The process scheme is shown in Fig.6. 


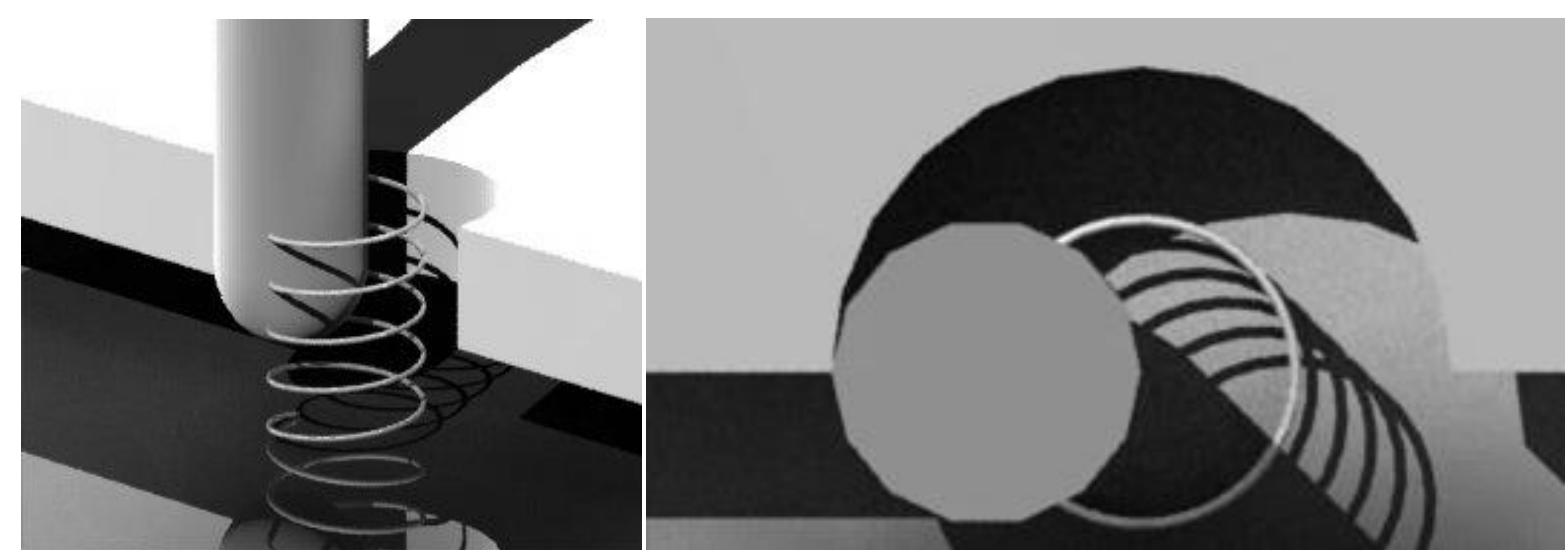

Fig. 6. Path followed by the ball helical milling process

Some advantages of this process compared to conventional drilling are listed below:

- Same tool for different hole diameters (high flexibility).

- More efficient chip evacuation (reduced contact time between chip, tool and machined surface).

- Burr minimization when milling because less plastic deformation occurs.

- Improved surface finish due to a higher rigidity of the tool respect to a conventional drill.

In order to improve the hole making process using conventional drilling, experimental test to evaluate the performance of ball helical milling were carried out on one of the most difficult of the $\gamma$-TiAl alloys, the TNB alloy. The tools used for the study were ball end mills $7 \mathrm{~mm}$ diameter, two flutes with TiAlN coating. The experiments were carried out in two stages; the first one to achieve the optimal cutting conditions due to the spherical profile of the tool provides more strenght compared to the end mill and conventional drill, and the second stage was aimed to understand the wear behaviour on the cutting edges and performance according to the demands of the hole making process.

The first stage of experiments were based on previous results from conventional drilling as well as from the observation of the wear rise under different conditions. Four different feed rates were evaluated $(0.014,0.017,0.020$ and $0.025 \mathrm{~mm} / \mathrm{tooth}$ ), under four different cutting speeds $(20,35,40$ and $50 \mathrm{~m} / \mathrm{min})$. The results shown a not very significant damage after three holes made with each combination.

The second stage of experiments consisted on two wear tests under medium and aggressive cutting conditions in order to compare the advantages of ball helical milling process versus conventional drilling. The cutting conditions are listed in Table 3. The time value showed in the table was measured for a $10 \mathrm{~mm}$ depth hole, considering a security distance of $2 \mathrm{~mm}$ and the exit relief of $3.5 \mathrm{~mm}$ for the tool tip. It can be observed form the comparison between the BHM and conventional drilling, there is insignificant difference in terms of productivity because the time necessary to accomplish a hole with conventional drilling is $2.1 \mathrm{~min}$ using the feasible cutting 
Beranoagirre, A.; Olvera, D.; Urbicain, G.; Lopez de Lacalle, L. N. \& Lamikiz, A.: Hole... conditions found in the previous section for a drill with $\mathrm{D}=10.75 \mathrm{~mm}\left(\mathrm{~V}_{\mathrm{c}}=10\right.$ $\mathrm{m} / \mathrm{min}, \mathrm{f}_{\mathrm{n}}=0.025 \mathrm{~mm} / \mathrm{rev}$ ).

\begin{tabular}{|l|r|l|l|l|}
\hline & & Test 1 & Test2 & \\
\hline Cuttingspeed & $\mathrm{V}_{\mathrm{c}}=$ & 50 & 70 & $\mathrm{~m} / \mathrm{min}$ \\
\hline Feed per tooth & $\mathrm{f}_{\mathrm{z}}=$ & 0.03 & 0.03 & $\mathrm{~mm} /$ thooth \\
\hline Helix step & $\mathrm{p}=$ & 0.5 & 0.5 & $\mathrm{~mm} / \mathrm{helixrev}$ \\
\hline Time per hole & $\mathrm{t}=$ & 2.82 & 2.01 & $\mathrm{~min}$ \\
\hline Tool life & $\mathrm{TL}=$ & $>>67$ & 42 & $\mathrm{~min}$ \\
\hline
\end{tabular}

Tab. 3. Cutting conditions for the wear tests

The graph of the tool life for both tests is shown in Fig. 7. Considering the results shown in the previous section (see Table 2 and Fig. 5), it can be stated that tool life for the ball end mill in the most aggressive conditions tested is at least 1.5 times the tool life of a conventional drill, taking into account the general criterion of tool wear $\mathrm{VB}<300 \mu \mathrm{m}$.

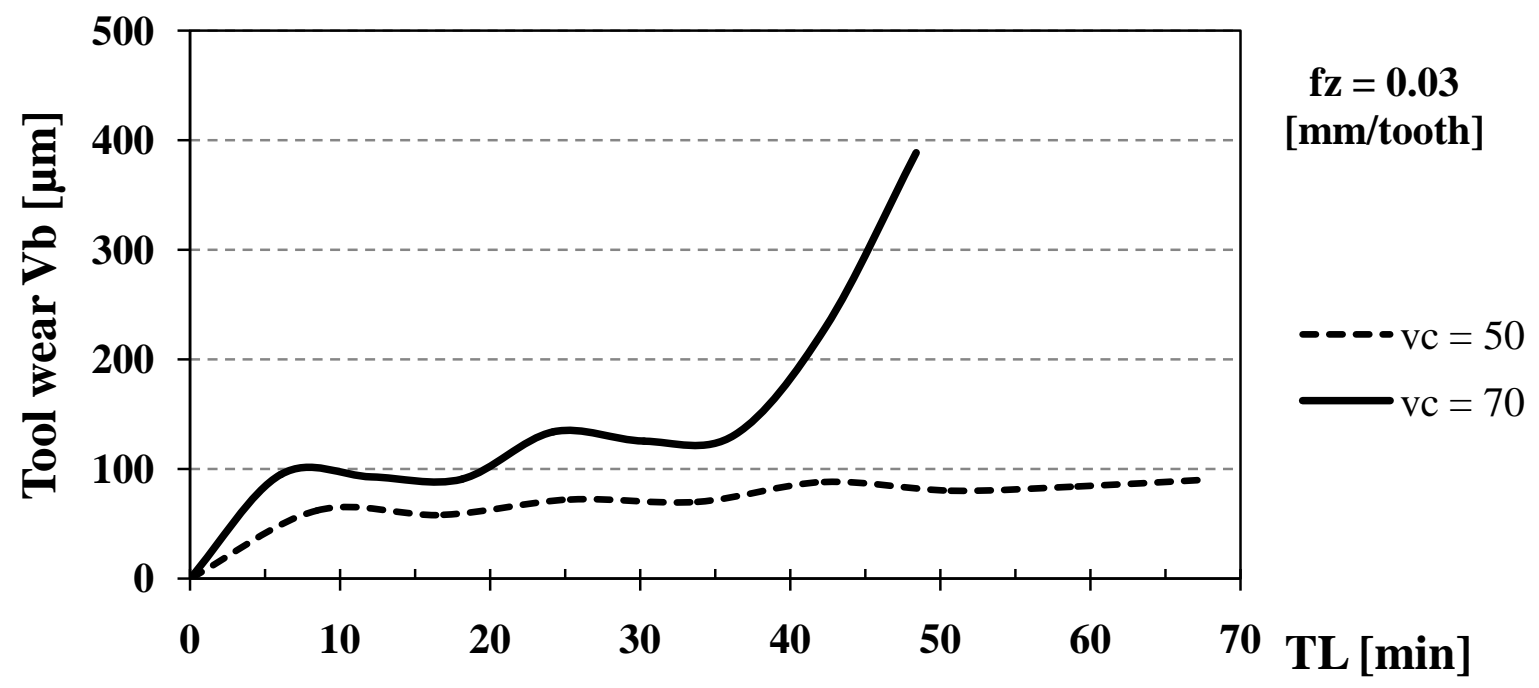

Fig. 7. Tool life in TNB for the BHM tools (TL=Tool Life)

Diameter measurements were carried out in a coordinate measuring machine at two different levels, $1 \mathrm{~mm}$ depth and $9 \mathrm{~mm}$ depth. The results from the wear tests showed a slight difference of the accuracy in the hole diameter between the upper and the lower measurements. For the upper diameter the difference to the nominal value was kept within $45 \mu \mathrm{m}$ meanwhile for the lower diameter was $90 \mu \mathrm{m}$. From the Figure 8 it can be observed the difference between the cutting speeds is negligible until the 18th hole. During the test using $\mathrm{V}_{\mathrm{c}}=70 \mathrm{~m} / \mathrm{min}$, the material presented a fragile fracture with a progressive propagation through the sub sequent machined holes. It is well known the brittle behavior of this kind of materials and the description of the causes opens a new research line to describe the main characteristics when such materials are machined. 


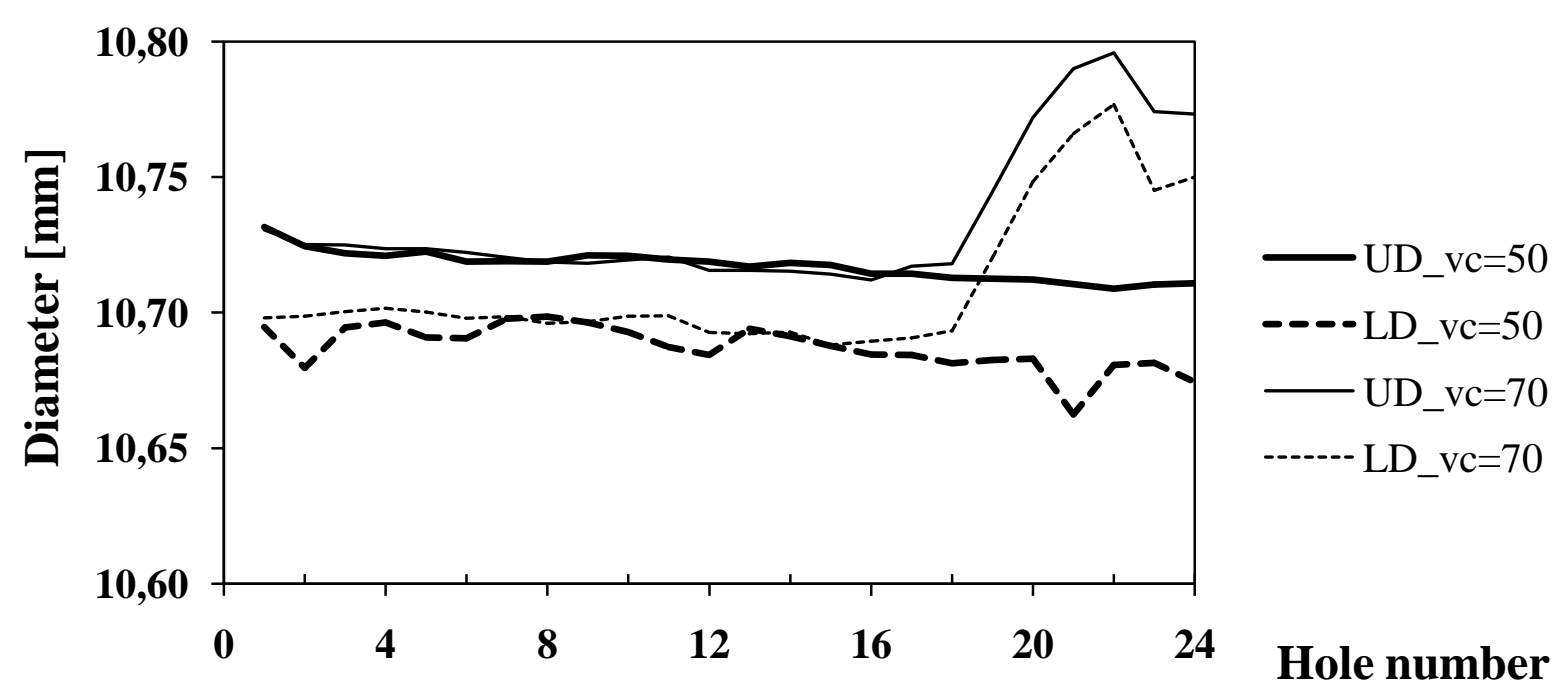

Fig. 8. Diameter achieved, Upper Diameter (UP) and Lower Diameter (LD)

The Figure 9 illustrates the brittle behaviour described above. This fracture has an important repercussion on the dimensional precision of the subsequent machined holes of the same row. It is clear from the Figure 8 the increase in the hole diameter measured from the 18th hole to the 24th. This interrupted the experiment in terms of accuracy but the time and the material removed remained useful for the wear analysis which was the main aim in this study.

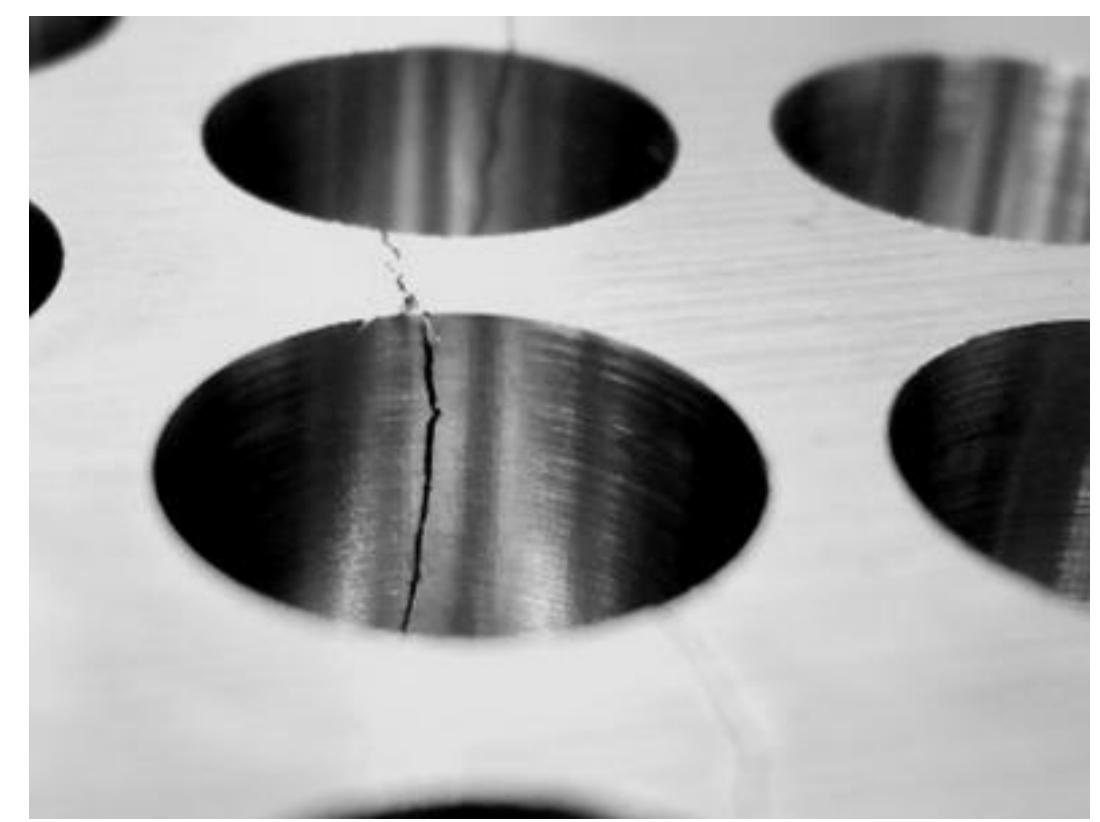

Fig. 9. Fragile fracture during BHM process on TNB alloy

\section{Discussion and conclusions}

During the present study was possible the evaluation of the hole making process on the difficult to cut $\gamma$-TiAl alloys with tungsten carbide coated tools using conventional drilling as well as ball helical milling. For these materials, the goal 
settles in obtain viable cutting parameters more than productivity because of their well known high mechanical properties.

The results obtained offer feasible cutting parameters in both, conventional drilling and ball helical milling processes. From them, it is possible to conclude that ball helical milling process, previously studied for difficult to cut materials such as Inconel 718 as well as Ti6Al4V, showed a better advantage over the conventional drilling process in terms of tool life and process performance, avoiding the use of subsequent process escommonly used after drilling to remove the burrs.

The BHM process was success fully applied on one of the most difficult to cut gamma TiAl alloys. The hole machining over TNB offers a perspective of the promising feasibility to use this process on the MoCuSi alloys.

The brittle behaviour of the TNB alloy was evident during simple hole making tests, even without a very high compressive stress process on an apparently strength plate $13.5 \mathrm{~mm}$ thick. Results make evident the current application scope of $\gamma$-TiAl alloys, and the inherent risk found during machining of high added value and high liability parts. Future work will be focused on the description of the circumstances which provoke the brittle behavior of the $\gamma$-TiAl alloys.

\section{References}

Aspinwal, D. K.; Dewes, R. C.; Mantle, A. L. (2005). The Machining of $\gamma$-TiAl Intermetallic Alloys, CIRP Annals -Manufacturing Technology, Vol. 54, Issue 1, (June 2007), pp. 99-104, ISSN 0007-8506

Iyer, R.;Koshy, P.; Ng, E. (2007). Helical milling: An enabling technology for hard machining precision holes in AISI D2 tool steel, International Journal of Machine Tools \& Manufacture, Vol. 47, (2007), pp. 205-210,ISSN 0890-6955

Loria, E. A. Quo vadis gamma titanium aluminide, Intermetallics, Vol. 9, Issue 12, (December 2001), pp.997-1001, ISSN0966-9795

Noda, T. Application of cast gamma TiAl for automobiles, Intermetallics, Vol. 6, Issues 7-8, (February 1999), pp. 709-713, ISSN 0966-9795

Sharman, A.R.C.; Aspinwall, D.K.; Dewesb, R.C.; Bowen, P. Workpiece surface integrity considerations when finish turning gamma titanium aluminide, Wear,Vol. 249, Issues 5-6 (June 2001), pp. 473-481, ISSN 0043-1648

Smit, M.A.; Sykes, J.M.; Hunter,J.A.; Sharman, J.D.B.; Scamans,G.M. Titanium based conversion coatings on aluminium alloy, Surface Engineering, Vol. 15, No. 5., (1999), pp. 407-410, ISSN 0267-0844 